\title{
MIMR THE INFLUENCE OF UNIQUE MELODIES OF PRASHASTHI AND KAMATH SONGS IN SRI LANKAN FOLK MUSIC ON HEART RATE
}

\author{
Isuru Dehideniya \\ Department of Musicology, University of Visual and Performing Arts, Colombo, Sri Lanka \\ Corresponding Author's E-mail: isurudehideniya@gmail.com
}

\begin{abstract}
Music plays an important role in our day to day life as a source of entertainment. More importantly music can also affect the other aspects of physical, mental, social and spiritual wellbeing of a person. According to Western and Eastern literature, heart rate correlates with certain musical aspects including tempo, melody, and music genre. The present research studied the variation of heart rate while listening to sedative and excitative Sri Lankan folk melodies. Prashasthi and Kamath folk musical creations have been selected for this experiment. Forty-five men between the ages of 25-30 who had never studied music were used as samples in this research. The mean heart rates of the subjects have increased significantly while listening to the prashasthi song. The mean heart of the subjects three minutes after stopping the prashasthi song remained significantly increased compared to their baseline $(p<0.01)$. Listening to Kamath songs did not significantly change the mean heart rates of the subjects.
\end{abstract}

Keywords: Heart Rate; Sri Lankan Folk Music; Sedative and Excitative Music; Prashasthi Songs; Kamath Songs

\section{INTRODUCTION}

The heart rate amplitudes from mental and physical stimulation for every moment. 1741 A.D Gretry has researched how human biological aspects respond to the music. Thereafter, many researchers have started studying the correlation of heart rate while listening to music (Dainow, 1977). Scholars have stated that listening to music affects the autonomic nervous system. As a result, it also affects the sympathetic and parasympathetic nervous system that controls the cardiovascular system (Valenti et al., 2012; Ferreira et al., 2015; Regaçone et al., 2014; Trappe \& Voit, 2016; Watanabe et al., 2017). Most of the researchers have found two common conclusions in general. First one, while listening to Excitative music, has possibly increased the heart rate. Second one, while listening to sedative music, has possibly decreased the heart rate (Iwanaga \& Tsukamoto, 1997; Valenti et al., 2012). But Hodges has summarized four contradictory results of the heart rate while listening to excitative and sedative music (Iwanaga \& Moroki, 1999). If they are; Heart rate increased during excitative music and decreased sedative music, both excitative and sedative music increased heart rate, both excitative and sedative music decreased heart rate, Music had no effect on heart rate.
According to researcher Iwanaga Mokoto, a listener prefers musical tempo that simply harmonize with his or her heart rate. A person has an average heart rate ranging from $62.8 \mathrm{bpm}$ to $92.1 \mathrm{bpm}$. Accordingly, the preferred musical tempo is between 70-100. However, a person will not prefer all musical tempos between 70 100. As an example, if the heart rate of a person was 70 $\mathrm{bpm}$ at a particular time, his preferred musical tempo will be 70 or second harmonic 105 or third harmonic 140. This density function indicated that preferred tempos were distributed mostly one, one and a half, and two times the heart rate (Iwanaga, 1995).

Current research has focused on the correlation between melodies of Sri Lankan folk music and heart rate. Many researchers in Western and Eastern music have studied the correlation between their musical tradition and human biological parameters. To date, a limited number of literatures are available regarding the effect of Sri Lankan musicon biological parameters of a human.

\section{METHODOLOGY}

This research has mainly focused on the specifics of sedative and excitative Sri Lankan Folk melodies. Western researchers have classified specificities of 
sedative and excitative music, Sedative music is characterized as melodious, delicate, harmonic and romantic while Excitative music characterized as loud, dynamic, rhythmic, elicited tension and excitement (Iwanaga et al., 2005). I have studied two folk musical creations which have above mentioned specific points in my research, Sunil Rathnasekara's "chandanam yasa" prashasthi folk musical creation as the excitative music; this includes the elements of excitative musical specificity. C. De S Kulathilaka's "O Raire Oi Rama " kamath folk musical creation as a sedative music; this includes the elements of sedative musical specificity.

For this research I have used a sample of forty-five healthy males aged between 25-30 years. Person with any mental and physical difficulties were excluded from the study. None of the subjects had acquired any form of higher education in music. The subjects were given headphones with noise cancellation and seated in a position of $90^{\circ}$ in a silent environment. Their eyes were covered with blinds. Three minutes before listening, two minutes and forty-five seconds while listening and three minutes after listening the song were used as time frames for testing the heart rate. The heart rate was measured every fifteen seconds during each session, using a pulse-oxymeter. All tested people in the research were subjected to two musical experiences, prashasthi and kamath songs with a six to eight hours interval in between.

\section{RESULTS}

Table 1: Average Heart Rates of Subjects at the Six Sessions Based on Prashasthi and Kamath Songs

\begin{tabular}{|c|c|c|c|c|c|c|}
\hline \multicolumn{7}{|c|}{ Beats Per Minute (bpm) } \\
\hline $\begin{array}{l}\text { Number of } \\
\text { Person }\end{array}$ & $\begin{array}{l}\text { Before listening } \\
\text { to prashasthi } \\
\text { song }\end{array}$ & $\begin{array}{l}\text { While listening } \\
\text { to prashasthi } \\
\text { song }\end{array}$ & $\begin{array}{l}\text { After listening } \\
\text { to prashasthi } \\
\text { song }\end{array}$ & $\begin{array}{l}\text { Before listening } \\
\text { to kamath song }\end{array}$ & $\begin{array}{l}\text { While listening } \\
\text { to kamath song }\end{array}$ & $\begin{array}{l}\text { After listening } \\
\text { to kamath song }\end{array}$ \\
\hline 1 & 84.23 & 82.75 & 89.23 & 88.46 & 89.25 & 85.38 \\
\hline 2 & 69.08 & 69.83 & 72.85 & 84.31 & 74.42 & 77.69 \\
\hline 3 & 62.08 & 64.42 & 65.92 & 61.00 & 62.25 & 61.46 \\
\hline 4 & 73.77 & 72.25 & 75.23 & 75.69 & 71.83 & 75.85 \\
\hline 5 & 69.77 & 72.58 & 71.54 & 72.54 & 72.75 & 72.31 \\
\hline 6 & 76.15 & 75.42 & 78.08 & 71.46 & 70.33 & 71.69 \\
\hline 7 & 66.92 & 71.42 & 71.38 & 68.15 & 70.33 & 68.08 \\
\hline 8 & 63.23 & 65.67 & 67.62 & 56.85 & 56.92 & 58.08 \\
\hline 9 & 76.77 & 79.58 & 81.46 & 70.31 & 71.25 & 70.92 \\
\hline 10 & 84.38 & 80.67 & 82.62 & 75.38 & 70.08 & 74.00 \\
\hline 11 & 76.38 & 82.08 & 82.15 & 88.69 & 88.67 & 87.85 \\
\hline 12 & 62.69 & 63.17 & 65.92 & 67.85 & 64.75 & 65.23 \\
\hline 13 & 57.08 & 59.08 & 58.69 & 60.38 & 59.42 & 59.31 \\
\hline 14 & 85.46 & 86.67 & 85.54 & 80.23 & 80.00 & 81.54 \\
\hline 15 & 65.85 & 63.67 & 65.23 & 63.31 & 69.33 & 64.92 \\
\hline 16 & 84.69 & 88.08 & 86.46 & 89.23 & 86.50 & 85.38 \\
\hline 17 & 64.38 & $\begin{array}{l}65.58 \\
\end{array}$ & 66.62 & 69.62 & 64.42 & 69.92 \\
\hline
\end{tabular}


$\underline{M}] \underline{M R}$ THE INFLUENCE OF UNIQUE FOLK MELODIES ON HEART RATE

\begin{tabular}{|c|c|c|c|c|c|c|}
\hline 18 & 62.15 & 63.58 & 65.15 & 61.08 & 64.67 & 64.69 \\
\hline 19 & 60.00 & 60.67 & 63.46 & 59.77 & 64.00 & 58.54 \\
\hline 20 & 65.23 & 65.58 & 66.54 & 60.00 & 60.83 & 63.31 \\
\hline 21 & 54.00 & 60.50 & 57.23 & 53.23 & 54.92 & 54.69 \\
\hline 22 & 78.00 & 84.92 & 84.31 & 73.77 & 75.75 & 78.08 \\
\hline 23 & 74.62 & 79.17 & 76.85 & 81.00 & 80.50 & 81.08 \\
\hline 24 & 92.00 & 91.92 & 93.92 & 84.92 & 84.17 & 82.08 \\
\hline 25 & 94.00 & 95.08 & 96.31 & 83.38 & 84.25 & 82.92 \\
\hline 26 & 70.57 & 73.75 & 73.69 & 71.08 & 74.00 & 74.92 \\
\hline 27 & 72.07 & 78.75 & 77.62 & 77.92 & 77.75 & 78.00 \\
\hline 28 & 70.43 & 76.67 & 73.92 & 74.31 & 77.50 & 74.08 \\
\hline 29 & 71.00 & 73.42 & 76.23 & 78.31 & 77.67 & 77.23 \\
\hline 30 & 85.64 & 92.25 & 91.23 & 79.54 & 82.33 & 80.85 \\
\hline 31 & 67.07 & 73.42 & 72.92 & 68.15 & 72.42 & 72.62 \\
\hline 32 & 102.57 & 106.33 & 104.85 & 95.46 & 97.00 & 97.31 \\
\hline 33 & 82.07 & 83.33 & 85.54 & 67.85 & 77.83 & 79.46 \\
\hline 34 & 70.14 & 80.58 & 75.85 & 67.62 & 77.17 & 70.15 \\
\hline 35 & 69.71 & 76.75 & 70.69 & 70.23 & 74.00 & 71.69 \\
\hline 36 & 72.79 & 77.67 & 72.77 & 71.31 & 79.42 & 76.85 \\
\hline 37 & 93.07 & 95.08 & 95.23 & 96.92 & 93.75 & 91.31 \\
\hline 38 & 59.86 & 65.17 & 64.38 & 62.85 & 68.42 & 69.69 \\
\hline 39 & 72.50 & 76.75 & 79.46 & 79.69 & 79.92 & 79.69 \\
\hline 40 & 66.64 & 67.58 & 70.23 & 77.00 & 71.50 & 74.54 \\
\hline 41 & 90.00 & 92.75 & 89.46 & 94.69 & 95.42 & 98.00 \\
\hline 42 & 81.50 & 84.50 & 86.62 & 73.31 & 71.50 & 73.38 \\
\hline 43 & 74.14 & 80.75 & 82.00 & 73.46 & 77.17 & 76.23 \\
\hline 44 & 88.43 & 91.33 & 91.92 & 82.23 & 84.17 & 85.31 \\
\hline 45 & 86.79 & 95.58 & 92.31 & 90.38 & 95.67 & 93.92 \\
\hline
\end{tabular}




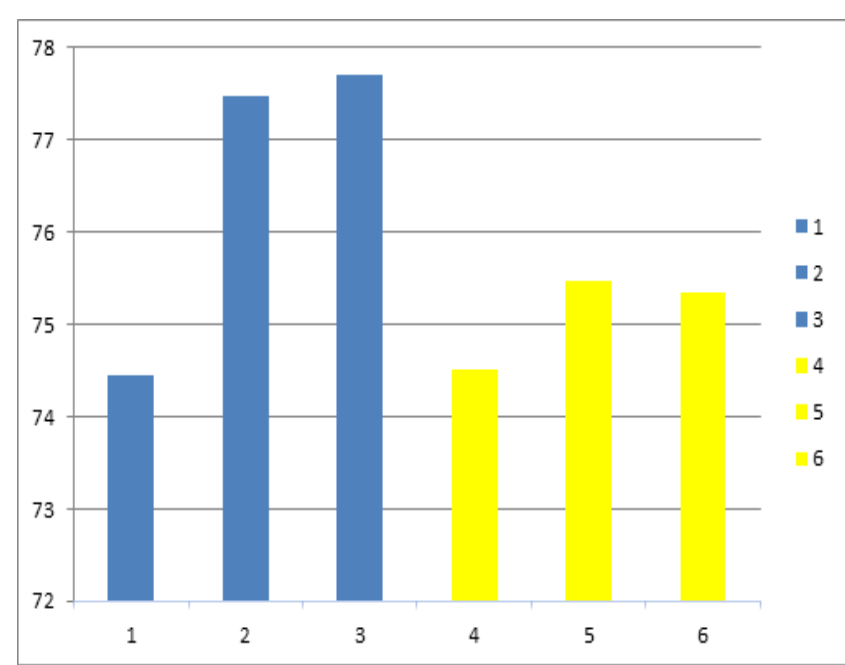

Figure 1: Final Averages of All Data

1. Before listening to prashasthi song- 74.44

2. While listening to prashasthi song- $77.48 \mathrm{bpm}$

3. After listening to prashasthi song- $77.72 \mathrm{bpm}$

4. Before listening to kamath song- $74.51 \mathrm{bpm}$

5. While listening to kamath song- $75.47 \mathrm{bpm}$

6. After listening to kamath song- $75.34 \mathrm{bpm}$

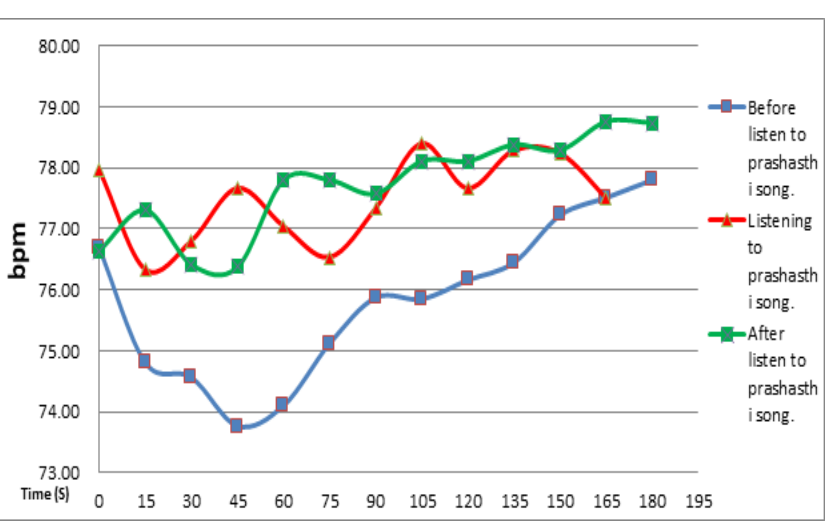

Figure 2: Three Situations Related to the Prashasthi Song

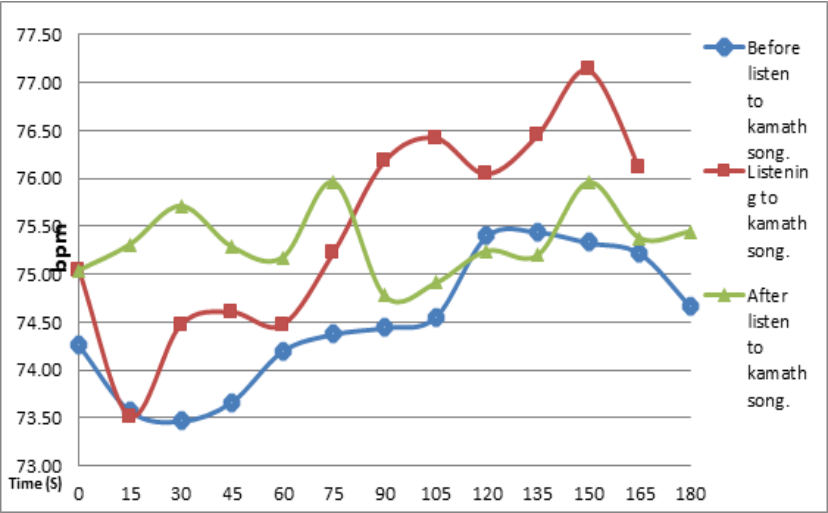

Figure 3: Three Situations Related to the Kamath Song

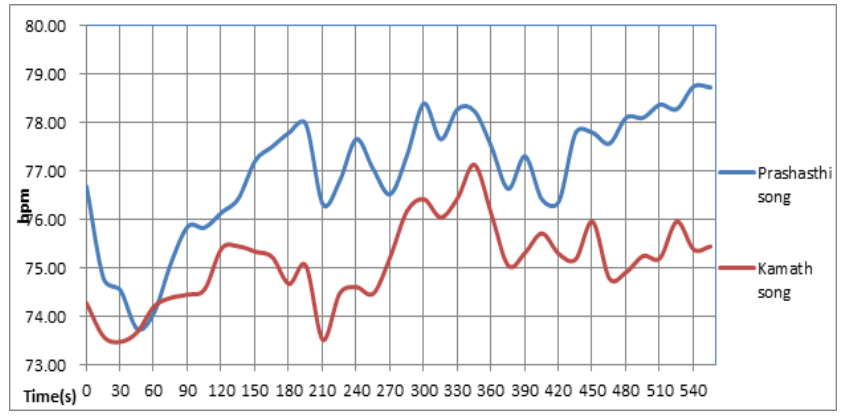

Figure 4: Three Situations Related to the Prashasthi Song and Kamath Song

Table 2: SPSS Software Analyzing.

\begin{tabular}{|l|l|c|c|c|c|c|c|c|}
\hline \multicolumn{7}{|c|}{ Paired Samples Test } \\
\hline
\end{tabular}

\section{DISCUSSION}

Heart rate is mainly controlled by the sympathetic nervous system and parasympathetic nervous system, which are parts of the autonomic nervous system (ANS). The sympathetic nervous system secretes catecholamine, epinephrine, norepinephrine hormones that increase the heart rate, while the parasympathetic nervous system secretes acetylcholine hormone that slows down the heart rate. Researchers Stefan Koelsch and Lutz Jancke have mentioned a valuable explanation as to how the heart rate and music are interconnected.

"Heart rate is regulated by numerous reflex-like circuits involving both brainstem structures and intra-thoracic cardiac ganglia, which are in turn under the influence of cortical forebrain structures involved in emotion such as the hypothalamus, amygdala, insular cortex, and orbitofrontal cortex. The activity of these forebrain structures can be modulated by music-evoked emotions. Generally, emotional arousal is associated with a predominance of sympathetic ANS activity, thus leading to an increase in Heart Rate, whereas a predominance of parasympathetic ANS activity leads 
to a decrease of Heart Rate." (Koelsch \& Jäncke, 2015)

Samangi and Sumanthri have studied stress reduction capability from the Sri Lankan Nalawili folk melody and other music genres. Accordingly, the heart rate has decreased in the sample as $87.5 \%$ for the Nalawili folk melody, $62.5 \%$ of the people for the weightless relaxation music, and $37.5 \%$ of the people for the Purwadanashri raga. Accordingly, there is a high tendency for the heart rate to decrease while listening to Nelawili songs in Sri Lankan folk music (Arachchi \& Samarawickrama, 2018). In this way, there is no additional research data to make a comparative discussion of the effect of listening to folk music in Sri Lanka on heart rate. But it can examine how to affect the heart rate while listening to different music genres in the world. For that should discuss of each one as western classical music, popular music, and Indian classical music.

According to the researchers, the music of the musicians Bach, Vivaldi, Mozart can significantly affect to the heart rate (Escher \& Evequoz, 1999). Researcher HansJoachim has studied the effects on the Cardiovascular System, based on four selected works in musician Mozart, five selected works in musician Strauss, and seven selected works in band ABBA. The Music of Mozart and Strauss have been shown to significantly reduce heart rate and blood pressure. But there has been no statistical response to the ABBA music. In particular, Hans-Joachim points out the musician Mozart's No. 40 in $\mathrm{g}$ minor (KV 550) symphony can have a powerful influence. Researcher Hans-Joachim Trappe who reviews the content of all the pieces of music that have been researched presents the characteristics of a piece of music that can have a positive effect on the Cardiovascular System such as a high degree of periodicity, a catchy melody line, a key that is experienced as pleasant, skillful composition, few changes in volume or rhythm, harmony sequences that are not rousing, the absence of sung words, a certain degree of prominence/fame and popularity of the musical genre (Trappe \& Voit, 2016). So also, Researcher Luciano Bernardi and his group, says that Vocal and orchestral crescendos have a significant correlation with the cardiovascular or respiratory compared to a monotonous piece of music (Bernardi et al., 2009).

According to a researcher named $\mathrm{R}$ Armon, the heart rate has increased significantly after listening to rock music genre (Armon et al., 2011). So also, David Sills, a researcher, has been examined musical genres under the tempo such as Classical- $125 \mathrm{bpm}$, Electronic- 119 bpm, Jazz- 154 bpm, World- 124 bpm, RNB- 99 bpm, and Rock- $79 \mathrm{bpm}$. But significant influences have been shown only in the genres of Classical and Rock. Also, the heart rate increased significantly when listening to the subjects' favourite musical selection (Sills \& Todd, 2015). Researcher Palakanis has among genres of classical, country/western, popular, Jazz/rhythm and blues, and gospel music to give the sample people in their most enjoyable music to listen. There, the heart rate decreased significantly (Palakanis et al., 1994). Samitha Siritunga and their team have studied the effects of listening for the raga called Darbarikanda on the Cardiovascular System. There, averages of blood pressure, heart rate, and the respiratory rate decreased significantly (Siritunga et al., 2013). According to Chatterjee, a researcher, Todi Raga significantly reduced blood pressure, pulse rate, and respiratory rate before hearing (Chatterjee \& Mukherjee, 2020). Also, according to a long-term study by a researcher named Gururaj, listening to Indian classical music has a significant effect on blood pressure (Kulkarni \& Chittapur, 2017). Researcher Nagarajan analyzed the heart rate before and after hearing Bhupali Raga. There, the Bhupali Raga can significantly decrease the heart rate (Nagarajan et al., 2015). In this way, elements of music can be clearly affected in the autonomic nervous system and the cardiovascular system, when listening to music in the various social samples of the world. Thus, the current research shows that the elements of folk music in Sri Lanka affect the heart rate.

\section{CONCLUSION}

The mean heart rates of the subjects have increased significantly while listening to the prashasthi song (the mean difference of the heart rate was 3.041with $99 \%$ confidence interval of 4.22 to $1.86(p<0.01)$. The mean heart of the subjects three minutes after stopping the prashasthi song remained significantly increased compared to their baseline $(p<0.01)$. Listening to Kamath songs did not significantly change the mean heart rates of the subjects.

\section{Conflicts of Interest:}

The authors declare that the research review was conducted in the absence of any commercial or economic associations that could be construed as a potential conflict of interest. 


\section{ACKNOWLEDGEMENT}

The author would like to acknowledge Doctor Indika Neluwa Liyanage, Lecturer at the Department of Biochemistry, Faculty of Medical Sciences, University of Sri Jayewardenepura, who was a visiting lecturer at university of visual and performing arts for valuable feedback and the assistant in statistical calculation. Second, he would like to give special thanks to all members who participated in this research sample. At this moment he would like to thank the lecturers in his university department. Prof. Kolitha Bhanu Disanayake, Dr. Anura Rathnasekara, Dr. Iranga weerakkody and temporary Assistant Lecturer Samitha Samarathunga have all improved my musicology knowledge.

\section{REFERENCES}

Arachchi, S. W., \& Samarawickrama, S. (2018). Sinhala traditional music of Sri Lanka for stress relief: an interaction design intervention. Sustainability for People, 431.

Armon, R., Goldfarb, B., \& Milton, C. (2011). Effects of Music Tempos on Blood Pressure Heart Rate and Skin Conductance After Physical Exertion. University of Wisconsin-Madison, 1-12.

Bernardi, L., Porta, C., Casucci, G., Balsamo, R., Bernardi, N. F., Fogari, R., \& Sleight, P. (2009). Clinical perspective. Circulation, 119(25), 31713180 .

Chatterjee, S., \& Mukherjee, R. (2020). Evaluation of the Effects of Music Therapy Using Todi Raga of Hindustani Classical Music on Blood Pressure, Pulse Rate and Respiratory Rate of Healthy Elderly Men. Journal of Scientific Research, 64, 159-166.

Dainow, E. (1977). Physical effects and motor responses to music. Journal of Research in Music Education, 25(3), 211-221.

Escher, J., \& Evequoz, D. (1999). Music and heart rate variability. Study of the effect of music on heart rate variability in healthy adolescents. Praxis, 88(21), 951-952.

Ferreira, L. L., Vanderlei, L. C. M., Guida, H. L., de Abreu, L. C., Garner, D. M., Vanderlei, F. M., ... \& Valenti, V. E. (2015). Response of cardiac autonomic modulation after a single exposure to musical auditory stimulation. Noise \& Health, 17(75), 108.https://doi.org/10.4103/1463-1741.153402.
Iwanaga, M. (1995). Harmonic relationship between preferred tempi and heart rate. Perceptual and Motor Skills, 81(1), 67-71. https://doi.org/10.2466/ pms.1995.81.1.67.

Iwanaga, M., \& Moroki, Y. (1999). Subjective and physiological responses to music stimuli controlled over activity and preference. Journal of Music Therapy, 36(1), 26-38.

Iwanaga, M., \& Tsukamoto, M. (1997). Effects of excitative and sedative music on subjective and physiological relaxation. Perceptual and Motor Skills, 85(1), 287-296.

Iwanaga, M., Kobayashi, A., \& Kawasaki, C. (2005). Heart rate variability with repetitive exposure to music. Biological Psychology, 70(1), 61-66.

Koelsch, S., \& Jäncke, L. (2015). Music and the heart. European Heart Journal, 36(44), 3043-3049.

Kulkarni, G. B., \& Chittapur, D. (2017). Effects of long term Indian classical Raga Therapy in reduction of Blood Pressure among chronic hypertensive patients. APIK Journal of Internal Medicine, 5(3), 10.

Nagarajan, K., Srinivasan, T. M., \& Rao, N. H. R. (2015). Immediate effect of Indian music on cardiac autonomic control and anxiety: A comparative study. Heart India, 3(4), 93.

Palakanis, K. C., DeNobile, J. W., Sweeney, W. B., \& Blankenship, C. L. (1994). Effect of music therapy on state anxiety in patients undergoing flexible sigmoidoscopy. Diseases of the Colon \& Rectum, 37(5), 478-481.

Regaçone, S. F., Lima, D. D., Banzato, M. S., Gução, A. C., Valenti, V. E., \& Frizzo, A. C. (2014). Association between central auditory processing mechanism and cardiac autonomic regulation. International Archives of Medicine, 7(1), 1-4. http://doi.org/10.1186/1755-7682-7-21.

Sills, D., \& Todd, A. (2015). Does Music Directly Affect a Person's Heart Rate?. Journal of Emerging Investigators, 1.

Siritunga, S., Wijewardena, K., Ekanayaka, R., \& Mudunkotuwa, P. (2013). Effect of music on blood pressure, pulse rate and respiratory rate of asymptomatic individuals: A randomized controlled trial.

Trappe, H. J., \& Voit, G. (2016). The cardiovascular 
effect of musical genres: a randomized controlled study on the effect of compositions by WA Mozart, J. Strauss, and ABBA. Deutsches Ärzteblatt International, 113(20), 347. doi: 10.3238/arztebl. 2016.0347.

Valenti, V. E., de Abreu, L. C., Guida, H. L., Vanderlei, L. C. M., Ferreira, L. L., \& Ferreira, C. (2012). Musical auditory stimulation and cardiac autonomic regulation. Complementary Therapies for the Contemporary Healthcare, 111. http://doi.org/10.5772/52186.

Watanabe, K., Ooishi, Y., \& Kashino, M. (2017). Heart rate responses induced by acoustic tempo and its interaction with basal heart rate. Scientific Reports, 7(1), 1-12. Retrieved from: https://www.ncbi. nlm.nih.gov/pmc/articles/PMC5339732/. 